\section{Management of hereditary angio-oedema with low-dose danazol}

Hereditary angio-oedema is an uncommon autosomal dominant disorder associated with low serum concentrations of $\mathrm{C} 1$ esterase inhibitor. It presents as recurrent swelling of the face, limbs, gut wall, or upper airway and is associated with considerable morbidity and mortality. Acute attacks affecting the airway are best treated with infusion of fresh-frozen plasma. Long-term prevention of attacks with antifibrinolytics or androgens has often been unsatisfactory owing to poor disease control or unacceptable side effects. ${ }^{1}$ Danazol (dosage $600 \mathrm{mg} /$ day), an androgen derivative, has recently been used successfully in preventing attacks while causing few side effects. ${ }^{2}$ The dose needed and the method of monitoring treatment, however, have not been established. We present two cases showing one approach.

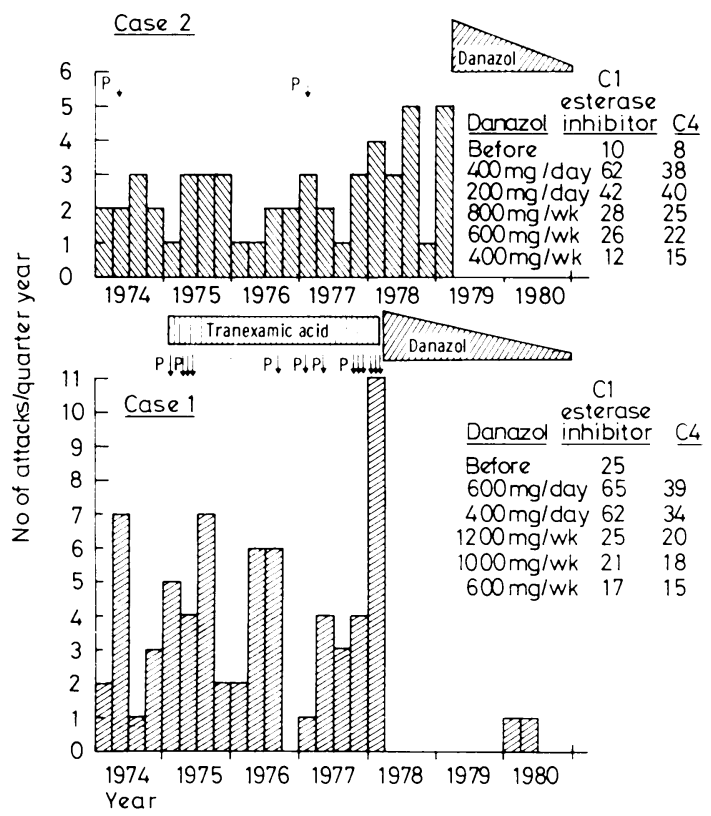

Effect of danazol on number of attacks of hereditary angiooedema and concentrations of $\mathrm{Cl}$ esterase inhibitor (expressed as \% of standard) and $\mathrm{C} 4(\mathrm{mg} / 100 \mathrm{ml})$ in cases 1 and 2. ( $\mathbf{P}_{\downarrow}$ denotes hospital treatment with fresh-frozen plasma.)

\section{Case reports}

Case 1-The patient, a 32-year-old man, had had recurrent attacks of hereditary angio-oedema since the age of 8 . He had required numerous hospital admissions because of orolaryngeal swelling and abdominal pain. His father had died aged 42 of laryngeal obstruction after years of recurrent attacks of hereditary angio-oedema. From 1974, when he came under our care, he kept a daily symptom diary (figure). In January 1975 an emergency laparotomy for acute abdominal pain disclosed only free peritoneal fluid. Tranexamic acid for three years made little difference to his symptoms. Attacks were interfering increasingly with his job as a welder. Danazol (600 $\mathrm{mg}$ /day) was started in April 1978: his symptoms stopped immediately and concentrations of $\mathrm{C} 1$ esterase inhibitor rose. The dose was subsequently reduced slowly to $200 \mathrm{mg}$ three times a week. Although the concentrations of $\mathrm{C} 1$ esterase inhibitor and C4 fell steadily, he had only two mild attacks (figure). He had no side effects except mild alopecia.

Case 2-This patient, a brother of the man reported on above, was a 30-year-old plate-metal worker who had had repeated attacks of hereditary angio-oedema since aged 16 . The daily symptom diary that he had kept from 1974 showed that he had had up to five attacks a quarter until danazol was started in May 1979 (figure). The dose was reduced gradually to $300 \mathrm{mg} /$ week with no attacks and no side effects. Concentrations of $\mathrm{Cl}$ esterase inhibitor and $\mathrm{C} 4$ rose dramatically when danazol was started and dropped progressively to pretreatment values as the dose was reduced (figure).

\section{Comment}

Danazol was extremely effective in preventing attacks of hereditary angio-oedema in these cases. The protective effect was maintained even as the dose was reduced progressively from $600 \mathrm{mg} /$ day towards
$300 \mathrm{mg} /$ week. Both patients were eventually able to do hard physical work, one on off-shore oil rigs.

The mode of action of danazol is not clear. Danazol increases concentrations of $\mathrm{C} 1$ esterase inhibitor and $\mathrm{C} 4$ within a few days of the start of treatment, ${ }^{2}$ and the concentrations seem to be directly related to the dose used, ${ }^{3}$ as shown in our cases. Complete disease control may be maintained, however, even as the concentrations fall back to pretreatment values as the dose is reduced." This may be either because danazol exerts an effect independent of the concentration of $\mathrm{Cl}$ esterase inhibitor or because only small increases in this concentration are necessary to prevent activation of the complement cascade.

Although danazol appears to have few side effects, ${ }^{25}$ nobody has taken it over a long period, as may be necessary for patients with hereditary angio-oedema. The minimum effective dose, which is probably less than $200 \mathrm{mg} /$ day, should therefore be found for each patient. This may be arrived at by titrating it against the patient's symptoms rather than serum concentrations of $\mathrm{Cl}$ esterase inhibitor. Our cases show that symptom diaries are ideal for controlling the treatment of such a chronic disease.

Measurements of complement concentrations were performed by the department of immunology, Queen's Medical Centre, Nottingham.

Requests for reprints should be sent to DD.

${ }^{1}$ Frank MM, Gelfand JA, Atkinson JP. Hereditary angioedema; the clinical syndrome and its management. Ann Intern Med 1976;84:580-93.

${ }^{2}$ Gelfand JA, Sherins RJ, Alling DW, Frank MM. Treatment of hereditary angioedema with danazol. Reversal of clinical and biochemical abnormalities. $N$ Engl f Med 1976;295:1444-8.

${ }^{3}$ Pitts JS, Donaldson VH, Forristal J, Wyatt RJ. Remissions induced in hereditary angioneurotic oedema with an attenuated androgen (danazol): correlation between concentrations of $\mathrm{Cl}$-inhibitor and the fourth and second components of complement. F Lab Clin Med 1978;92:501-7.

4 Warin AP, Gatecliff M, Greaves MW, Warin RP, Williamson DM. The treatment of hereditary angio-oedema with low dose androgenic drugs. Br f Dermatol 1979;101, suppl:18-9.

5 Atkinson JP. Diagnosis and management of hereditary angioedema. Ann Allergy 1979;42:348-52.

(Accepted 21 fanuary 1981)

Department of Thoracic Medicine, City Hospital, Nottingham NG5 1PD

J T MACFARLANE, MA, MRCP, senior medical registrar

D DAVIES, MD, FRCP, consultant physician

\section{Infantile acne associated with transient increases in plasma concentrations of luteinising hormone, follicle-stimulating hormone, and testosterone}

I report a case of infantile acne associated with transient increases in concentrations of luteinising hormone, follicle-stimulating hormone, and testosterone and postulate that these abnormalities were due to delay in maturation of the hypothalamic "gonadostat."

\section{Case report}

The boy (figure) was admitted aged 11 months with a four-week history of vomiting and a rash on the cheeks, present since the age of 6 weeks. Examination showed obvious recent weight loss and malar acne. Genitalia were normal, the testes size being 1-2 $\mathrm{ml}$. The vomiting proved to be due to rumination.

A random plasma cortisol concentration was raised at $859 \mathrm{nmol} / \mathrm{l}$ $(31.1 \mu \mathrm{g} / 100 \mathrm{ml})$, thought to be consistent with stress. Bone age, determined radiologically, was about 1 year. An echoencephalogram and renal-adrenal ultrasound examination were normal. A skull $x$-ray film showed possible slight enlargement of the pituitary fossa. Random concentrations of luteinising and follicle-stimulating hormones at 13 months were raised at $5.4 \mathrm{U} / 1$ and $17.1 \mathrm{U} / 1$ respectively (normal values at this age $<2.5 \mathrm{U} / 1$ and $<2 \mathrm{U} / 1$ respectively). His rumination settled and he thrived, but he was readmitted at 15 months in view of the abnormal findings. The acne persisted despite treatment, but examination was otherwise normal, although penis 
size was thought to be in the upper-normal range. Testicular volume remained $1-2 \mathrm{ml}$.

At 15 months plasma diurnal cortisol concentrations were normal. A combined insulin hypoglycaemia test for growth hormone and cortisol and tests for thyrotrophin-releasing hormone and luteinising hormone-releasing hormone gave normal results, basal concentrations of luteinising and follicle-stimulating hormones being 2.1 and $<0.4 \mathrm{U} / 1$ respectively. Basal thyroxine, triiodothyronine, and prolactin concentrations were normal. Urinary free cortisol, plasma $17 \alpha$-hydroxyprogesterone, dehydroepiandrosterone sulphate, and androstenedione; 24-hour urinary 17-oxosteroids, 17-oxogenic steroids, and 17-hydroxycorticosteroids; and ultrasound

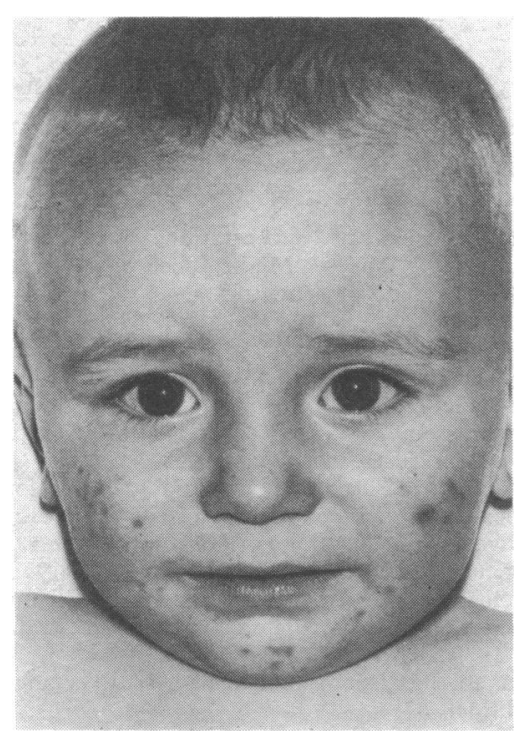

Acne on infant's face.

examination of the adrenals and intravenous pyelography were normal. The pituitary fossa on skull $x$-ray examination was thought to be of omega type, a normal variant. Plasma testosterone concentration was $2.4 \mathrm{nmol} / 1$ (692 $\mathrm{pg} / \mathrm{ml})\left(\right.$ normal $0.23 \pm S D 0.09 \mathrm{nmol} / 1(66 \pm 26 \mathrm{pg} / \mathrm{ml})$ at that age. ${ }^{1}$

He was followed up and continued to thrive, though his acne persisted. At 26 months the acne was much improved, examination was otherwise normal, and a random plasma testosterone concentration was $<0.5 \mathrm{nmol} / 1$ (144 $\mathrm{pg} / \mathrm{ml})$.

\section{Comment}

Infantile acne is rare. Several drugs may cause acne but none were ingested by this patient. Exceptionally, infantile acne may be associated with an excess of androgens-for example, in Cushing's syndrome. Bessone ${ }^{2}$ studied over 60 patients with infantile acne $(80 \%$ being boys) and found that the onset was usually in the first 12 months. Virtually all subjects showed no evidence of other androgenic abnormalities, but many had an abnormally high excretion of 17ketogenic steroids. Infantile acne often lasts until the age of 3 or 4 years but may persist longer. ${ }^{3}$

A normal boy has a neonatal rise in plasma concentrations of luteinising and follicle-stimulating hormones lasting for three to four months ${ }^{4}$ and associated with a transient rise in plasma testosterone to a peak at 1 month in the low adult range (mean peak values $9 \cdot 3 \pm 1 \cdot 1$ $\left.\mathrm{nmol} / \mathrm{l}(2682 \pm 317 \mathrm{pg} / \mathrm{ml})^{1}\right)$. This returns to normal prepubertal values by 7 months $(0 \cdot 25 \pm 0 \cdot 14 \mathrm{nmol} / 1(72 \pm 40 \mathrm{pg} / \mathrm{ml}))$.

Investigations showed no cause for the transient abnormalities in hormone concentrations in this boy. The hypothalamopituitarygonadal negative feedback mechanism functions at this age, and the prepubertal hypothalamic "gonadostat"3 (the sensitivity of the feedback mechanism) appears to mature from birth, when it has a high threshold of sensitivity, to become set at a low threshold of sensitivity from 7 months until shortly before puberty, when it alters again to have a high threshold of sensitivity. ${ }^{1}$ Possibly this patient had a prolonged period of immaturity of the gonadostat with a high threshold of sensitivity. The findings are similar to those in isolated premature thelarche ${ }^{5}$ when transient increases in plasma luteinising and follicle-stimulating hormones and $17 \beta$-oestradiol are found. I suggest that similar studies should be done on a group of infants with acne to see whether these findings are unique or a common mechanism.
I am grateful to Dr J K Grant and Dr J G Ratcliffe and staff, department $\underline{\underline{\sigma}}$ of biochemistry, Glasgow Royal Infirmary, for carrying out the steroid and radioimmune assays.

${ }^{1}$ Forrest MG. Differentiation and development of the male. In: Butt WR, London DR, eds. The testis. London: W B Saunders, 1975:569-96. (Clinics in Endocrinology and Metabolism 1975;4:No 3.)

${ }^{2}$ Bessone L. L'eruzione acneiforme corticotropane e cortisonica nell' infanzia. Chronica Dermatologica 1974;1:77.

${ }^{3}$ Cunliffe WJ, Cotterill JA. Clinical features of the acnes. In: Cunliffe: WJ Cotterill JA, eds. The acnes: clinical features, pathogenesis and treatment. London: W B Saunders, 1975:10-49.

4 Winter JSD, Faiman C, Hobson WC, Prasad AV, Reyes FI. Pituitarygonadal relations in infancy. 1. Patterns of serum gonadotrophin concentrations from birth to four years of age in man and chimpanzee. f Clin Endocrinol Metab 1975;40:545-55.

${ }^{5}$ Bierich JR. Sexual precocity. In: Bierich JR, ed. Disorders of puberty. London: W B Saunders, 1975:107-42. (Clinics in Endocrinology and Metabolism $1975 ; 4$ : No 1 .)

(Accepted 26 fanuary 1981)

Royal Hospital for Sick Children, Glasgow G3 8SJ

E M C DUKE, MRCP, DCH, senior registrar

\section{Enterotoxic effect of methotrexate: does it influence the drug's absorption in children with acute lymphoblastic leukaemia?}

Xylose malabsorption occurs in children with acute lymphoblastic leukaemia receiving methotrexate maintenance treatment, ${ }^{1}$ and it has been suggested that either an acute ${ }^{2}$ or a cumulative ${ }^{3}$ toxic effect on the small gut may be associated with the drug's malabsorption. We studied the relation between absorption of methotrexate and xylose and both the standard five-day oral course of methotrexate (acute effect) and a prolonged period of maintenance treatment (cumulative effect).

\section{Patients, methods, and results}

We studied 32 children aged 3-15 (mean 7·1) years with acute lymphoblastic leukaemia : all were in remission being treated according to a UKALL trial protocol, most taking either a single weekly dose of methotrexate or a five-day course every three or four weeks. After an overnight fast a venous

Mean $( \pm S E M)$ methotrexate absorption profiles and blood xylose concentrations in eight patients on first and fifth days of a course of methotrexate and in nine patients receiving regular methotrexate studied at an interval

\begin{tabular}{|c|c|c|c|c|c|}
\hline & $\begin{array}{c}\text { Peak } \\
\text { methotrexate } \\
\text { concentration } \\
(\mu \mathrm{mol} / \mathrm{l})\end{array}$ & $\begin{array}{l}\text { Time of peak } \\
\text { concentration } \\
\text { (hours) }\end{array}$ & $\begin{array}{c}\text { Rate of } \\
\text { absorption } \\
(\mu \mathrm{mol} / \mathrm{h})\end{array}$ & $\begin{array}{c}\text { Area under } \\
\text { curve } \\
(\mu \mathrm{mol} \mathrm{h} / \mathrm{l})\end{array}$ & $\begin{array}{c}\text { One- } \\
\text { hour } \\
\text { blood } \\
\text { xylose } \\
(\text { mmol/1) }\end{array}$ \\
\hline \multicolumn{6}{|c|}{ Patients receiving five-day course } \\
\hline $\begin{array}{l}\text { Day } 1 \\
\text { Day } 5\end{array}$ & $\begin{array}{l}0.89 \pm 0.10 \\
0.93 \pm 0.11\end{array}$ & $\begin{array}{l}1.8 \pm 0.3 \\
1.5 \pm 0.1\end{array}$ & $\begin{array}{l}0.83 \pm 0.15 \\
0.85 \pm 0.15\end{array}$ & $\begin{array}{l}2 \cdot 2 \pm 0 \cdot 4 \\
2 \cdot 2 \pm 0 \cdot 2\end{array}$ & $\begin{array}{l}0.9 \pm 0.1 \\
1.1 \pm 0.1\end{array}$ \\
\hline \multicolumn{6}{|c|}{ Patients receiving maintenance treatment } \\
\hline \multirow{2}{*}{$\begin{array}{l}\text { First study } \\
\text { Repeat } \\
\text { study }\end{array}$} & $0.90 \pm 0.16$ & $1 \cdot 8 \pm 0 \cdot 2$ & $0 \cdot 75 \pm 0 \cdot 16$ & $1 \cdot 6 \pm 0.3$ & $1 \cdot 2 \pm 0 \cdot 2$ \\
\hline & $0.96 \pm 0 \cdot 12$ & $1.6 \pm 0.3$ & $0 \cdot 92 \pm 0 \cdot 18$ & $2 \cdot 2 \pm 0 \cdot 5$ & $1 \cdot 0 \pm 0 \cdot 2$ \\
\hline
\end{tabular}

Conversion: SI to traditional units-Methotrexate: $1 \mu \mathrm{mol} / 1 \approx 45.4 \mu \mathrm{g} / 100 \mathrm{ml}$. $\mathrm{Xylose:} 1 \mathrm{mmol} / \approx 15 \mathrm{mg} / 100 \mathrm{ml}$.

cannula was inserted and a resting blood sample withdrawn. Methotrexate $\left(15 \mathrm{mg} / \mathrm{m}^{2}\right.$ ) was given with water, and further samples were obtained at 20 , 40,60 , and 90 minutes and at two, three, and four hours. Serum was separated and stored at $-20^{\circ} \mathrm{C}$ until analysed by immunoassay (Emit, Maidenhead) within two weeks. The "blood xylose concentration" was the difference between the resting value and that one hour after $5 \mathrm{~g}$ of $\mathrm{D}$-xylose was given in $50 \mathrm{ml}$ water. 